\title{
Influência da cobertura do solo e doses de nitrogênio na cultura do milho safrinha
}

\author{
Francisco E. Torres ${ }^{1}$, Luiz C. F. de Souza ${ }^{2}$, Lúcio H. L. de Andrade', Fernanda F. Pedroso²,
} Aline de O. Matoso ${ }^{3}$, Leonardo D. Torres ${ }^{4}$, Cleiton G. S. Benett ${ }^{5} \&$ Katiane S. S. Benett ${ }^{5}$

\footnotetext{
1 Universidade Estadual de Mato Grosso do Sul, Unidade de Aquidauana, Rodovia Aquidauana-CERA Km 12, Zona Rural, CEP 79200-000, Aquidauana-MS, Brasil. Caixa Postal 25. E-mail: feduardo@uems.br; lucioagronomia@yahoo.com

2 Universidade Federal da Grande Dourados, Faculdade de Ciências Agrárias, Rodovia Dourados-Itaum, km 12, CEP 79804-970, Dourados-MS, Brasil. Caixa Postal 533. E-mail: luizsouza@ufgd.edu.br; ferpedroso@gmail.com

${ }^{3}$ Universidade Estadual Paulista Júlio de Mesquita Filho, Faculdade de Ciências Agronômicas de Botucatu, Departamento de Agricultura e Melhoramento Vegetal, Rua José Barbosa de Barros, 1780, Jardim Paraiso, CEP 18610-307, Botucatu-SP, Brasil. Caixa Postal 237. E-mail: alinematoso@hotmail.com

${ }^{4}$ Engenheiro Agrônomo, Mestrando UEMS, Bolsista FUNDECT. E-mail: torrinhos@hotmail.com

${ }^{5}$ Universidade Estadual de Goiás, Agronomia, Rodovia GO 330, Km 241, Anel Viário, s/n, Setor Universitário, CEP 75780-000, Ipameri-GO, Brasil. E-mail: cbenett@hotmail.com; kasantiago@ig.com.br
}

\section{RESUMO}

A utilização da cobertura do solo e a adubação nitrogenada em cobertura no sistema de plantio direto, além de essenciais para a conservação do solo podem também auxiliar na disponibilidade de nutrientes para as plantas sucessoras. 0 objetivo deste trabalho foi avaliar a influência de três diferentes plantas de cobertura de solo e quatro níveis de adubação nitrogenada na cultura do milho safrinha em sistema de plantio direto. O experimento foi conduzido no Núcleo Experimental de Ciências Agrárias da Universidade Federal da Grande Dourados, Dourados-MS. O delineamento experimental foi o de blocos ao acaso no esquema fatorial $3 \times 4$, sendo três coberturas do solo (mucuna preta, uma área em pousio com capim camalote e outra com crotalária) e quatro doses de nitrogênio $\left(0,40,80\right.$ e $\left.120 \mathrm{~kg} \mathrm{ha}^{-1}\right)$, com quatro repetições. Foram avaliados a altura da planta e a inserção da espiga, diâmetro do colmo, o diâmetro e o comprimento de espigas, o peso de cem grãos e a produtividade. A cobertura do solo influenciou no diâmetro basal do colmo e na produtividade de grãos de milho. $O$ incremento das doses de nitrogênio favoreceu a grande maioria dos componentes de produção da cultura do milho. A utilização das coberturas como mucuna preta e capim camelote e as doses de nitrogênio, aumentaram a produtividade de grãos de milho.

Palavras-chave: conservação do solo, produtividade, Zea mays L.

\section{Influence of cover crops and nitrogen rates in winter corn crop}

\begin{abstract}
The use of cover crops along with the nitrogen application in no-tillage system, besides being essential for the conservation of soil, can also assist in nutrient availability to succeeding crops. The aim of this study was to evaluate the influence of three different ground cover plants and four levels of nitrogen fertilization on winter maize under no-tillage system. The experiment was conducted at the Experimental Center of Agricultural Sciences of the Universidade Federal da Grande Dourados, Dourados-MS. The experiment was conducted in randomized blocks in a 3x4 factorial design, with three ground covers (velvet bean, an area under fallow with 'camalote' grass and another with sunn hemp) and four levels of nitrogen (0.40.80 and $120 \mathrm{~kg} \mathrm{ha}^{-1}$ ), with four replications. The plant height and ear height, stem diameter, the diameter and length of ears, weight of hundred grains and productivity of winter corn were evaluated. Soil cover influenced the basal stem diameter and grain yield of maize. The increment of nitrogen favored the vast majority of yield components of corn. The use of hedges such as velvet bean and grass camelote and nitrogen increased the grain yield of maize.
\end{abstract}

Key words: soil conservation, productivity, Zea mays L. 


\section{Introdução}

A cultura do milho (Zea mays L.) apresenta alto potencial de produção sendo de grande importância econômica devido ao valor nutricional de seus grãos, tanto para a alimentação humana como animal e industrial.

O milho safrinha é caracterizado pelo cultivo em sequeiro com semeadura realizada nos meses de janeiro a abril, após a cultura de verão, geralmente após a soja precoce, sendo produzidos principalmente nos estados do Paraná, São Paulo, Goiás, Mato Grosso e Mato Grosso do Sul (Cruz et al., 2010).

Com o incremento da área em sistema de plantio direto na região do cerrado, muitos ganhos têm sido alcançados em conservação do solo. $\mathrm{O}$ sucesso do sistema de plantio direto depende, entre outros fatores, da escolha da espécie que será semeada em sucessão para a produção de fitomassa necessária para manutenção do sistema de plantio (Oliveira et al., 2002).

Para Santos et al. (2010) a maioria dos solos brasileiros apresenta teores insuficientes de nitrogênio, havendo, então, a necessidade de seu fornecimento, seja na forma mineral ou orgânico, com a implantação de leguminosas como adubação verde.

O aumento da produtividade do milho em função da cultura antecessora demonstra que esta prática é viável (Collier et al., 2006; Silva et al., 2006) e deve ser estudada e adaptada a cada região visto que algumas espécies não têm introduzido melhorias na produtividade do milho no centro-oeste (Martins \& Rosa Junior, 2005).

O uso de plantas de cobertura, ou seja, a adubação verde é uma prática promissora e viável, pois resultados de pesquisas comprovam sua eficiência em relação à cobertura e proteção do solo, tanto quanto na melhoria das condições físicas, químicas e biológicas (Santos et al., 2010).

O cultivo de adubos verdes, sobretudo de leguminosas, antecedendo a cultura do milho em sistema de plantio direto, tem demonstrado ser uma alternativa promissora na suplementação de nitrogênio para a cultura sucessora (Gonçalves et al., 2000).

A disponibilidade de nitrogênio no solo durante o ciclo de desenvolvimento da cultura tem grande influência sobre a produtividade de grãos de milho sendo que, este elemento pode não apenas limitar a produtividade de grãos mas também proporcionar maiores produtividades da cultura (Bortolini et al., 2001).

A utilização do nitrogênio na forma de ureia é a fonte mais empregada no Brasil porém com a limitação de que, quando aplicada na superfície do solo, há chances de perda por volatilização de $\mathrm{NH}_{3}$ (Valderrama et al., 2011). Desta forma, a utilização de nitrogênio juntamente com a cobertura do solo, pode influenciar na produtividade de grãos amenizando as quantidades de nitrogênio mineral para a cultura do milho.

Neste contexto, o presente trabalho teve por objetivo avaliar a influência de três diferentes plantas de cobertura de solo e quatro níveis de adubação nitrogenada na cultura do milho safrinha em sistema de plantio direto.

\section{Material e Métodos}

O experimento foi conduzido no Núcleo Experimental de Ciências Agrárias da Universidade Federal da Grande
Dourados, Dourados, Estado do Mato Grosso do Sul, localizado entre $22^{\circ} 14^{\prime}$ de latitude $\mathrm{S}$ e $54^{\circ} 56^{\prime}$ de longitude $\mathrm{W}$, com altitude média de $458 \mathrm{~m}$ e topografia plana. O solo da área experimental é classificado como Latossolo Vermelho distroférrico, textura argilosa, sob vegetação de cerrado (Embrapa, 2006). O clima é considerado Cwh, de acordo com a classificação de Köppen, com a temperatura do mês mais frio situando-se entre $-3^{\circ} \mathrm{C}$ a $18^{\circ} \mathrm{C}$; possui período seco de inverno e temperatura média anual maior que $18^{\circ} \mathrm{C}$.

O delineamento experimental utilizado foi o de blocos ao acaso no esquema fatorial $3 \times 4$, sendo três coberturas do solo (mucuna preta, uma área em pousio com capim camalote $\mathrm{e}$ outra com crotalária) e quatro doses de nitrogênio $(0,40,80 \mathrm{e}$ $120 \mathrm{~kg} \mathrm{ha}^{-1}$ ), com quatro repetições.

Anterior à instalação do experimento, a área foi cultivada em sistema de plantio direto com sucessão soja-milho nas últimas safras e as culturas de cobertura foram semeadas em janeiro de 2009. Os atributos químicos do solo das três áreas de cobertura foram determinados antes da instalação do experimento, segundo metodologia proposta por van Raij et al. (2001), com os seguintes resultados: mucuna preta: $\mathrm{pH}$ em $\mathrm{CaCl}_{2}=5,3$; matéria orgânica $(\mathrm{MO})=23,8 \mathrm{~g} \mathrm{dm}^{-3} ; \mathrm{P}=21,4$ $\mathrm{mg} \mathrm{dm}{ }^{-3} ; \mathrm{K}=2,9 \mathrm{mmol}_{\mathrm{c}} \mathrm{dm}^{-3} ; \mathrm{Ca}=42,0 \mathrm{mmol}_{\mathrm{c}} \mathrm{dm}^{-3} ; \mathrm{Mg}=21,0$ mmol $\mathrm{dm}^{-3}$ e CTC $=106,3 \mathrm{mmol}_{\mathrm{c}} \mathrm{dm}^{-3}$; área em pousio com capim camalote: $\mathrm{pH}$ em $\mathrm{CaCl} 2=4,7$; matéria orgânica $(\mathrm{MO})=$ $25,5 \mathrm{~g} \mathrm{dm}^{-3} ; \mathrm{P}=36,0 \mathrm{mg} \mathrm{dm}^{-3} ; \mathrm{K}=6,7 \mathrm{mmol}_{\mathrm{c}} \mathrm{dm}^{-3} ; \mathrm{Ca}=35,5$ $\mathrm{mmol}_{\mathrm{c}} \mathrm{dm}^{-3} ; \mathrm{Mg}=15,0 \mathrm{mmol}_{\mathrm{c}} \mathrm{dm}^{-3}$ e CTC $=120,2 \mathrm{mmol}_{\mathrm{c}} \mathrm{dm}^{-3}$; crotalária: $\mathrm{pH}$ em $\mathrm{CaCl} 2=4,6$; matéria orgânica $(\mathrm{MO})=24,1 \mathrm{~g}$ $\mathrm{dm}^{-3} ; \mathrm{P}=21,0 \mathrm{mg} \mathrm{dm}^{-3} ; \mathrm{K}=4,2 \mathrm{mmol}_{\mathrm{c}} \mathrm{dm}^{-3} ; \mathrm{Ca}=33,8 \mathrm{mmol}_{\mathrm{c}} \mathrm{dm}^{-}$ 3; $\mathrm{Mg}=13,5 \mathrm{mmol}_{\mathrm{c}} \mathrm{dm}^{-3}$ e CTC $=119,5 \mathrm{mmol}_{\mathrm{c}} \mathrm{dm}^{-3}$.

As culturas de cobertura foram manejadas com rolo-faca no florescimento pleno, sendo a rebrota dessecada com o herbicida glyphosate, na dose de $0,75 \mathrm{~L} \mathrm{ha}^{-1}$.

A semeadura do milho ocorreu sobre os resíduos culturais dessas espécies, com semeadora de plantio direto utilizando-se o híbrido simples DKB 350, sendo cultivadas em quatro linhas com cinco metros de comprimento, com espaçamento de 0,90 $\mathrm{m}$ entre linhas e população de 55 mil plantas ha ${ }^{-1}$, na segunda quinzena de março de 2009. A adubação de manutenção de semeadura foi realizada utilizando-se $300 \mathrm{~kg} \mathrm{ha}^{-1}$ da fórmula NPK 07-20-20, conforme (Ribeiro et al., 1999).

A adubação de nitrogênio em cobertura foi realizada manualmente a lanço, sobre a superfície do solo, em uma única aplicação, no estádio de quatro folhas completamente desenvolvidas, utilizando-se a ureia como fonte de $\mathrm{N}$.

O controle de plantas daninhas foi em pós-emergência utilizando-se o herbicida nicossulfuron na dose de 1,2 L ha 1. A Spodoptera frugiperda foi controlada com o inseticida fisiológico diflubenzuron, na dose de $100 \mathrm{~g} \mathrm{ha}^{-1}$, cuja área recebeu irrigação suplementar por aspersão em épocas críticas para a cultura.

Foram avaliados a altura da planta e a inserção da espiga, o diâmetro do colmo, o diâmetro e o comprimento de espigas, o peso de cem grãos e a produtividade. Para avaliar a produção de grãos tomaram-se as duas linhas centrais de cada parcela. A produtividade foi determinada após a debulha das espigas colhidas corrigindo-se o grau de umidade para $13 \%$, sendo os valores expressos em $\mathrm{kg} \mathrm{ha}^{-1}$. 
Os dados foram submetidos à análise de variância pelo (teste F) e quando as médias apresentavam nível de significância foi comparada pelo teste de Tukey a $5 \%$ de probabilidade para coberturas do solo enquanto para as doses de nitrogênio foram realizadas análises de regressão.

\section{Resultados e Discussão}

Avaliando os resultados contidos na Tabela 1 verificou-se que não houve efeito significativo das coberturas do solo para a altura de planta, altura de inserção da primeira espiga, número de fileiras de grãos por espiga, número de grãos por espiga e massa de grãos por espiga; também não foi constatado efeito significativo para as cobertura e doses de nitrogênio para essas avaliações (Tabela 1). Mesmo não havendo influência das coberturas do solo nas variáveis acima citadas, elas servem de proteção do solo evitando a ocorrência de erosão, o aumento da temperatura na camada superior do solo e pode ser fonte de nitrogênio na fase inicial para a cultura do milho devido o $\mathrm{N}$ das coberturas ser liberado rapidamente.

Cruz et al. (2008) verificaram, observando os componentes de produção de cultivares de milho e doses de nitrogênio em sistema de plantio direto que doses de $\mathrm{N}$ superiores a $80 \mathrm{~kg} \mathrm{ha}^{-1}$ não contribuíram para o aumento da altura de planta.

Para as doses de nitrogênio observou-se diferença significativa para a altura de inserção da primeira espiga, número de grãos por espiga e massa de grãos por espiga (Figura 1).

A altura de inserção da primeira espiga se ajustou a uma regressão quadrática com ponto de máximo com valor em $66,83 \mathrm{~kg} \mathrm{ha}^{-1}$ de N (Figura 1a). Tais resultados são diferentes dos encontrados por Valderrama et al. (2011) e Schiavinatti et al. (2011), que não observaram efeito significativo da aplicação de nitrogênio na altura da inserção da espiga.

Quanto ao número de grãos por espiga e massa de grãos por espiga ajustaram a regressão linear positiva (Figura $1 \mathrm{~b}$ e 1c, respectivamente). Souza et al. (2011) constataram, trabalhando com doses de $\mathrm{N}$ na cultura do milho safrinha, efeito significativo para o número de grãos por espiga, cujos dados se ajustaram à regressão quadrática; já para os resultados encontrados de Oliveira \& Caires (2003) e os não constataram

Tabela 1. Valores médios da altura de planta (AP), altura de inserção da primeira espiga (AIPE), número de fileiras de grãos por espiga (NFG), número de grãos por espiga (NGE) e massa de grãos por espiga (MGE) em função das coberturas do solo e doses de nitrogênio na cultura do milho safrinha

\begin{tabular}{lccccc}
\hline \multirow{2}{*}{ Tratamentos } & AP & AIPE & NFG & NGE & MGE \\
\cline { 2 - 6 } & \multicolumn{2}{c}{$(\mathbf{c m})$} & \multicolumn{2}{c}{ (unid.) } & $\mathbf{( g )}$ \\
\hline Cobertura do solo & & & & & \\
Mucuna preta & $180,50 \mathrm{a}$ & $98,38 \mathrm{a}$ & $16,83 \mathrm{a}$ & $563,41 \mathrm{a}$ & $169,79 \mathrm{a}$ \\
Capim camalote & $178,27 \mathrm{a}$ & $97,20 \mathrm{a}$ & $17,00 \mathrm{a}$ & $569,33 \mathrm{a}$ & $169,64 \mathrm{a}$ \\
Crotalária & $174,14 \mathrm{a}$ & $94,30 \mathrm{a}$ & $16,67 \mathrm{a}$ & $568,08 \mathrm{a}$ & $165,47 \mathrm{a}$ \\
\hline Doses de N (kg ha- $\left.{ }^{-1}\right)$ & & & & & \\
0 & 172,93 & 92,26 & 16,67 & 516,00 & 149,38 \\
40 & 180,46 & 98,71 & 17,11 & 556,66 & 162,94 \\
80 & 179,05 & 100,25 & 16,67 & 582,33 & 172,17 \\
120 & 178,10 & 95,28 & 16,88 & 612,77 & 187,71 \\
\hline $\mathrm{CV}(\%)$ & 3,53 & 6,10 & 5,94 & 7,39 & 8,46 \\
\hline
\end{tabular}

Médias seguidas pela mesma letra na coluna não diferem entre si pelo teste de Tukey a $5 \%$ de probabilidade
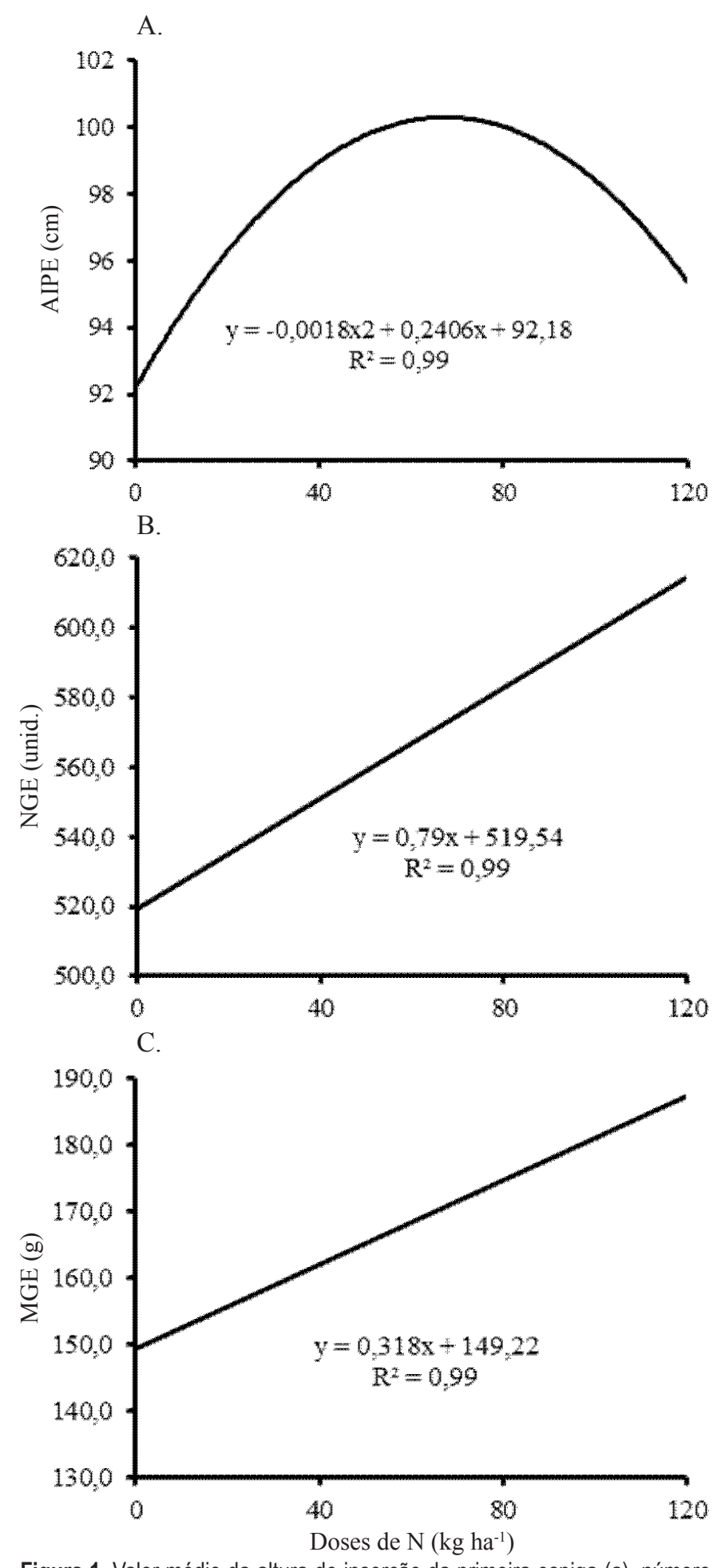

Figura 1. Valor médio da altura de inserção da primeira espiga (a), número de grãos por espiga (b) e massa de grãos por espiga (c) em função das doses de nitrogênio na cultura do milho safrinha

diferenças significativas das doses de $\mathrm{N}$ no número de grãos por espiga.

O diâmetro basal do colmo foi, no entanto, influenciado pelas coberturas do solo (Tabela 2) em que o capim camalote diferiu somente da mucuna preta. Para os valores de comprimento de espiga, diâmetro de espiga e massa de cem grãos, não foi observada influência das coberturas do solo sobre essas variáveis (Tabela 2). Ohland et al. (2005) trabalhando com 
Tabela 2. Valores médios do diâmetro basal do colmo (DBC), comprimento de espiga (CESP), diâmetro de espiga (DESP), massa de cem grãos (M100) e produtividade de grãos (PROD) em função das coberturas do solo e doses de nitrogênio na cultura do milho safrinha

\begin{tabular}{lccccc}
\hline \multirow{2}{*}{ Tratamentos } & DBC & CESP & DESP & $\begin{array}{c}\text { M100 } \\
\text { (g) }\end{array}$ & $\begin{array}{c}\text { PROD } \\
\text { kg ha }^{-1}\end{array}$ \\
\cline { 2 - 4 } Cobertura do solo & & $\mathbf{( c m )}$ & & & \\
Mucuna preta & $18,87 \mathrm{~b}$ & $15,49 \mathrm{a}$ & $4,99 \mathrm{a}$ & $30,35 \mathrm{a}$ & $7477 \mathrm{a}$ \\
Capim camalote & $21,05 \mathrm{a}$ & $15,67 \mathrm{a}$ & $4,97 \mathrm{a}$ & $30,26 \mathrm{a}$ & $7331 \mathrm{a}$ \\
Crotalária & $19,83 \mathrm{ab}$ & $15,05 \mathrm{a}$ & $4,89 \mathrm{a}$ & $29,35 \mathrm{a}$ & $6684 \mathrm{~b}$ \\
\hline Doses de N (kg ha-1) & & & & & \\
0 & 17,06 & 14,50 & 4,84 & 29,51 & 7205 \\
40 & 20,13 & 14,93 & 4,92 & 30,03 & 6357 \\
80 & 20,20 & 15,70 & 4,93 & 29,82 & 7406 \\
120 & 22,29 & 16,48 & 5,11 & 30,60 & 7688 \\
\hline $\mathrm{CV}(\%)$ & 10,03 & 6,34 & 2,26 & 6,01 & 7,18 \\
\hline
\end{tabular}

Médias seguidas da mesma letra na coluna, não diferem entre si pelo teste de Tukey a $5 \%$ de probabilidade.

coberturas do solo e adubação nitrogenada, não verificaram efeito significativo para o comprimento de espiga.

Para a variável produtividade de grãos (Tabela 2) as coberturas do solo mucuna preta e capim camalote diferiram significativamente da crotalária, com (793 e $\left.647 \mathrm{~kg} \mathrm{ha}^{-1}\right)$, respectivamente. Santos et al. (2010) verificaram, trabalhando com adubo verde e adubação nitrogenada, que a crotalária júncea, a crotalária spectabilis e o feijão-de-porco contribuíram,

A.

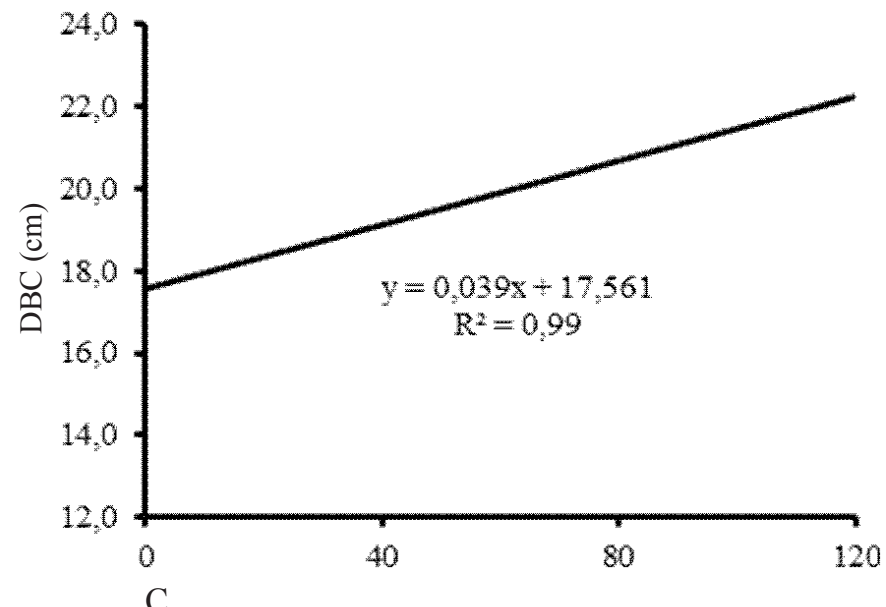

C.

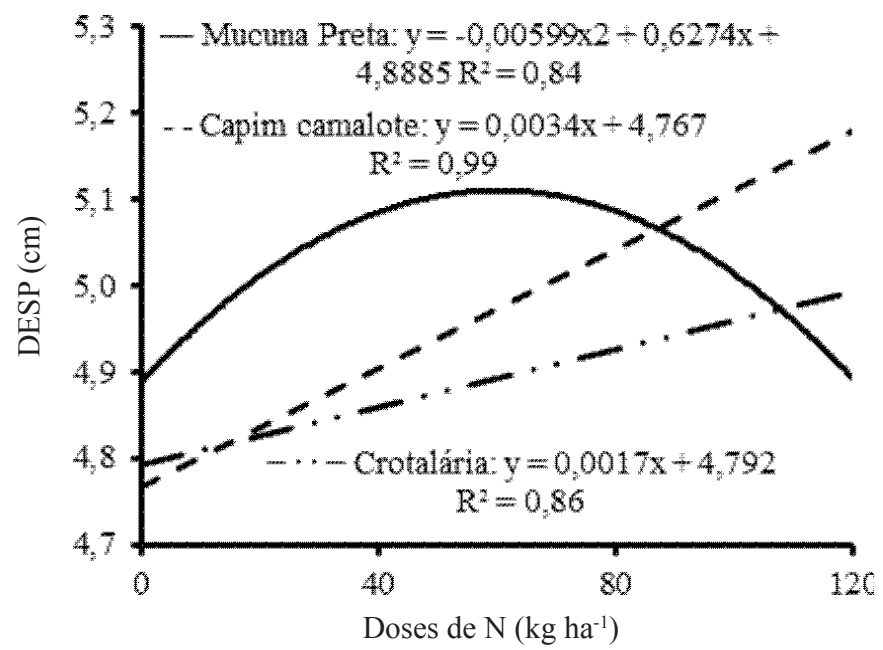

como culturas antecessoras ao milho, para maior produtividade da cultura. Conforme Weber \& Mielniczuk (2009) na ausência da adubação nitrogenada mineral a utilização de leguminosas aumenta a produtividade do milho.

As doses de nitrogênio influenciaram positivamente o diâmetro da base do colmo e o comprimento de espiga, com os dados se ajustando a uma equação linear crescente (Figura 2a e 2b). Silva et al. (2012) trabalhando com diferentes fontes e doses de ureia no milho, também observaram efeito significativo das doses de $\mathrm{N}$ para a variável diâmetro de colmo. Resultados diferentes foram obtidos por Valderrama et al. (2011) que não observaram efeito significativo da aplicação de $\mathrm{N}$ para o diâmetro da base do colmo e Schiavinatti et al. (2011) constataram que as maiores doses de $\mathrm{N}$ fornecidas em cobertura resultaram em colmos mais finos uma vez que na fase de crescimento vegetativo há maior demanda do elemento para a produção de tecidos na planta, resultados diferentes aos encontrados neste trabalho. Goes et al. (2012) trabalhando com doses de $\mathrm{N}$ na cultura do milho safrinha, não verificaram qualquer efeito significativo da aplicação do nitrogênio em cobertura.

Silva et al. (2006); Tomazela et al. (2006) obserrvaram, trabalhando com doses de nitrogênio maiores que $200 \mathrm{~kg} \mathrm{ha}^{-1}$ de $\mathrm{N}$, aumento do comprimento de espiga na cultura do milho.

B.

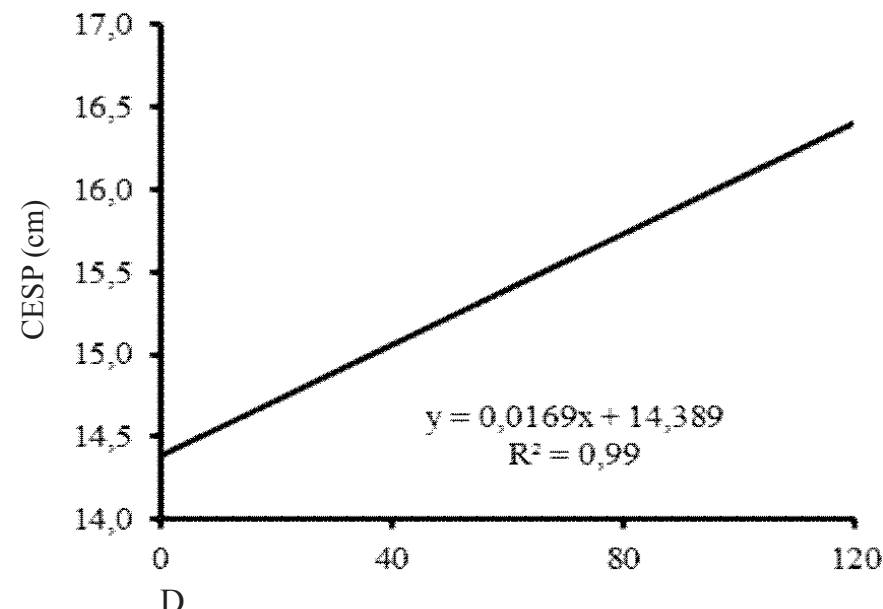

D.

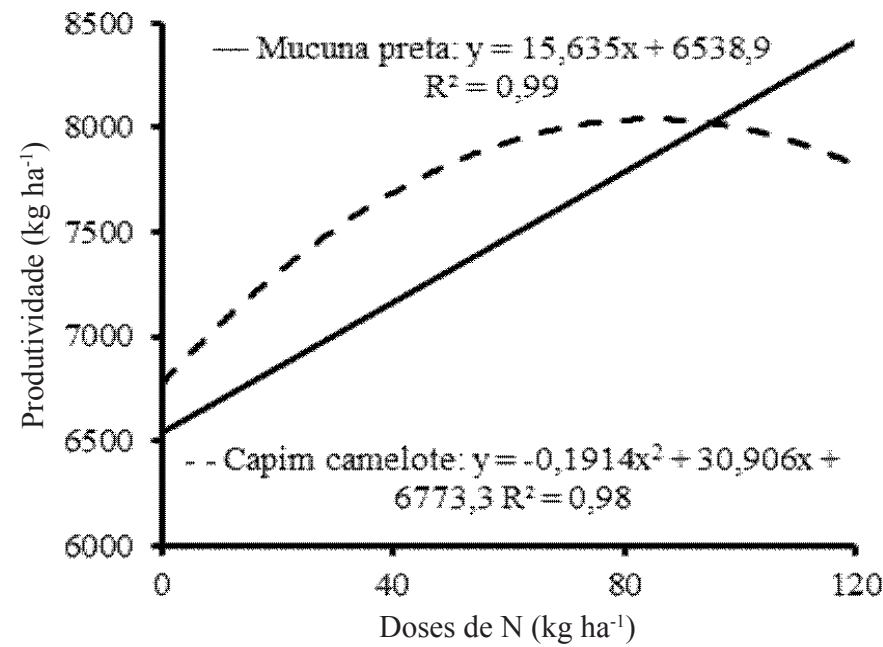

Figura 2. Valores médios do diâmetro basal do colmo (a), comprimento de espiga (b) para doses de nitrogênio e interação da cobertura e doses de nitrogênio para o diâmetro de espiga (c) e produtividade de grãos (d) na cultura do milho safrinha 
Observou-se interação entre coberturas do solo e doses de nitrogênio para o diâmetro de espiga e produtividade de grãos (Figura 2c e 2d). Os valores do diâmetro de espiga, dados referentes à cobertura do solo mucuna preta, se ajustaram a regressão quadrática com ponto de máximo estimado em $52,37 \mathrm{~kg} \mathrm{ha}^{-1}$ de $\mathrm{N}$; já para as coberturas com capim camalote e crotalária se ajustaram à regressão linear positiva (Figura 2c).

O diâmetro de espiga está estreitamente relacionado com o enchimento de grãos e o número de fileiras de grãos por espiga, que também é influenciado pelo genótipo (Ohland et al., 2005).

Para a produtividade de grãos as coberturas do solo se ajustaram à regressão linear positiva para mucuna preta $\mathrm{e}$ regressão quadrática com ponto de máximo de $80,74 \mathrm{~kg} \mathrm{ha}^{-1}$ de N para o capim camelote (Figura 2d). Ohland et al. (2005) trabalhando com coberturas do solo e adubação nitrogenada, não verificaram interação para a produtividade de grão; já Farinelli \& Lemos (2010) obtiveram ajuste quadrático da produtividade em função do aumento da dose de $\mathrm{N}$ em cobertura alcançando a máxima produtividade com $92 \mathrm{~kg} \mathrm{ha}^{-1}$ de $\mathrm{N}$ e Oliveira \& Caires (2003) observaram que a adubação nitrogenada em cobertura aumentou linearmente a produção de milho até a dose de $120 \mathrm{~kg} \mathrm{ha}^{-1}$ de N, sinalizando, para a obtenção de altas produtividades de milho, que após o cultivo de gramíneas (aveia preta), no sistema de plantio direto, é necessário o suprimento de doses elevadas de $\mathrm{N}$, enquanto Silva et al. (2012); Veloso et al. (2006) e Silva et al. (2005) constataram aumentos na produtividade com aumento da adubação nitrogenada na cultura do milho. Segundo Valderrama et al. (2011) o desenvolvimento da cultura do milho depende muito do histórico da área, das condições climáticas e dos estádios de aplicação do nitrogênio na cultura.

\section{Conclusões}

A cobertura do solo influenciou no diâmetro basal do colmo e na produtividade de grãos de milho.

$\mathrm{O}$ incremento das doses de nitrogênio favoreceu a grande maioria dos componentes de produção da cultura do milho.

A utilização das coberturas, como mucuna preta e capim camelote e nas doses de nitrogênio, aumentaram a produtividade de grãos de milho.

\section{Literatura Citada}

Bortolini, C. G.; Silva, P. R. F.; Argenta, G.; Forsthofer, E. L. Rendimento de grãos de milho cultivado após aveia-preta em respostas a adubação nitrogenada e regime hídrico. Pesquisa Agropecuária Brasileira, v.36, p.1101-1106, 2001. $<$ http://www.scielo.br/pdf/pab/v36n9/6469.pdfs. 02 nov. 2012.

Collier, L. S.; Castro, D. V.; Dias Neto, J. J.; Brito, D. R.; Ribeiro, P. A. A. Manejo da adubação nitrogenada para o milho sob palhada de leguminosas em plantio direto em Gurupi, TO. Ciência Rural, v.36, n.4, p.1100-1105, 2006. <http://dx.doi.org/10.1590/S0103-84782006000400009>.
Cruz, J. C.; Silva, G. H.; Pereira Filho, I. A.; Gontijo Neto, M. M.; Magalhães, P. C. Caracterização do cultivo de milho safrinha de alta produtividade em 2008 e 2009. Revista Brasileira de Milho e Sorgo, v.9, n.2, p.177-188, 2010. $<$ http://rbms.cnpms.embrapa.br/index.php/ojs/article/ view/311/365>. 11 Mar. 2013.

Cruz, S. C. S.; Pereira, F. R. S.; Santos, J. R.; Albuquerque, A. W.; Pereira, R. G. Adubação nitrogenada para o milho cultivado em sistema plantio direto, no Estado de Alagoas. Revista Brasileira de Engenharia Agrícola e Ambiental, v.12， n.1， p.62-68, 2008. <http://dx.doi.org/10.1590/ S1415-43662008000100009>.

Empresa Brasileira de Pesquisa Agropecuária - Embrapa. Centro Nacional de Pesquisa de Solos. Sistema brasileiro de classificação de solos. Rio de Janeiro, 2006. 412p.

Farinelli, R.; Lemos, L. B. Produtividade e eficiência agronômica do milho em função da adubação nitrogenada e manejos de solo. Revista Brasileira de Milho e Sorgo, v.9, n.32, p.135-146, 2010. <http://rbms.cnpms.embrapa. br/index.php/ojs/article/view/299/362>. 13 Mar. 2013.

Goes, R. J.; Rodrigues, R. A. F.; Arf, O.; Vilela, R. G. Nitrogênio em cobertura para o milho (zea mays 1.) Em sistema plantio direto na safrinha. Revista Brasileira de Milho e Sorgo, v.11, n.2, p.169-177, 2012. <http://rbms.cnpms.embrapa. br/index.php/ojs/article/view/379/pdf_22>. 03 Abr. 2013.

Gonçalves, C. N.; Ceretta, C. A.; Basso, C. J. Sucessões de culturas com plantas de cobertura e milho em plantio direto e sua influência sobre o nitrogênio do solo. Revista Brasileira de Ciência do Solo, v.24, n.1, p.153-159, 2000. $<$ http://sbcs.solos.ufv.br/solos/revistas/v24n1a17.pdf $>03$ Mai. 2013.

Martins, R. M. G.; Rosa Junior, E. J. Culturas antecessoras influenciando a cultura de milho e os atributos do solo no sistema de plantio direto. Acta Scientiarum Agronomy, v.27, n.2, p.225-232, 2005. <http://dx.doi.org/10.4025/ actasciagron.v27i2.1485>.

Ohland, R. A. A.; Souza, L. F.; Hernani, L. C.; Marchetti, M. E.; Gonçalves, M. C. Culturas de cobertura do solo e adubação nitrogenada no milho em plantio direto. Ciência e Agrotecnologia, v.29, n.3, p.538-544, 2005. <http://dx.doi. org/10.1590/S1413-70542005000300005>.

Oliveira, J. M. S.; Caires, E. F. Adubação nitrogenada em cobertura para o milho cultivado após aveia preta no sistema plantio direto. Acta Scientiarum Agronomy, v.25, n.2, p.351-357, 2003. <http://dx.doi.org/10.4025/ actasciagron.v25i2.1926>.

Oliveira, T. K.; Carvalho, G. J.; Moraes, R. N. S. Plantas de cobertura e seus efeitos sobre o feijoeiro em plantio direto. Pesquisa Agropecuária Brasileira, v.37, n.8, p.1079-1087, 2002. <http://dx.doi.org/10.1590/S0100204X2002000800005>.

Raij, B. Van; Andrade, J. C.; Cantarella, H.; Quaggio, J. A. Análise química para avaliação da fertilidade de solos tropicais. Campinas: Instituto Agronômico, 2001. 285p.

Ribeiro, A. C.; Guimarães, P. T. G.; Alvarez V. V. H. (Eds.). Recomendações para o uso de corretivos e fertilizantes em Minas Gerais. $5^{\text {a }}$ Aproximação. Viçosa: UFV, 1999. 359p. 
Santos, P. A.; Silva, A. F.; Carvalho, M. A. C.; Caione, G. Adubos verdes e adubação nitrogenada em cobertura no cultivo do milho. Revista Brasileira de Milho e Sorgo, v.9, n.2, p.123-134, 2010. <http://rbms.cnpms.embrapa.br/ index.php/ojs/article/view/305/361>. 11 Mar. 2013.

Schiavinatti, A. F.; Andreotti, M.; Benett, C. G. S.; Pariz, C. M.; Lodo, B. N.; Buzetti, S. Influência de fontes e modos de aplicação de nitrogênio nos componentes da produção e produtividade do milho irrigado no cerrado. Bragantia, v.70, n.4, p.925-930, 2011. <http://dx.doi.org/10.1590/ S0006-87052011000400027>.

Silva, A. A.; Silva, T. S.; Vasconcelos, A. C. P.; Lana, R. M. Q. Aplicação de diferentes fontes de ureia de liberação gradual na cultura do milho. Bioscience Journal, v.28, sup.1, p.104-111, 2012. <http://www.seer.ufu.br/index. php/biosciencejournal/article/view/13242>. 11 Mar. 2013.

Silva, D. A.; Vitorino, A. C. T.; Souza, L. C. F.; Gonçalves, M. C.; Roscoe, R. Culturas antecessoras e adubação nitrogenada na cultura do milho, em sistema plantio direto. Revista Brasileira de Milho e Sorgo, v.5, n.1, p.7588，2006. <http://rbms.cnpms.embrapa.br/index.php/ojs/ article/view/172/170>. 18 Nov. 2012.

Silva, E. C.; Ferreira, S. M.; Silva, G. P.; Assis, R. L.; Guimarães, G. L. Épocas e formas de aplicação de nitrogênio no milho sob plantio direto em solo de cerrado. Revista Brasileira de Ciência do Solo, v.29, n.5, p.725-733, 2005. <http://dx.doi. org/10.1590/S0100-06832005000500008>.
Souza, J. A.; Buzetti, S.; Teixeira Filho, M. C. M.; Andreotti, M.; Sá, M. E.; Arf, O. Adubação nitrogenada na cultura do milho safrinha irrigado em plantio direto. Bragantia, v.70, n.2, p.447-454, 2011. <http://dx.doi.org/10.1590/S0006$87052011000200028>$.

Tomazela, A. D.; Favarin, J. L.; Fancelli, A. L.; Martin, T. N.; Dourado Neto, D.; Reis, A. R. Doses de nitrogênio e fontes de $\mathrm{Cu}$ e $\mathrm{Mn}$ suplementar sobre a severidade da ferrugem e atributos morfológicos do milho. Revista Brasileira de Milho e Sorgo, v.5, n.2, p.192-201, 2006. <http://rbms. cnpms.embrapa.br/index.php/ojs/article/view/182/179>. 18 Nov. 2012.

Valderrama, M.; Buzetti, S.; Benett, C. G. S.; Andreotti, M.; Teixeira Filho, M. C. M. Fontes e doses de NPK em milho irrigado sob plantio direto. Pesquisa Agropecuária Tropical, v.41, n.2, p.254-263, 2011. <http://dx.doi.org/10.5216/pat. v41i2.8390>.

Veloso, M. E. C.; Duarte, S. N.; Dourado Neto, D.; Miranda, J. H.; Silva, E. C.; Sousa, V. F. Doses de nitrogênio na cultura do milho, em solos de várzea, sob sistema de drenagem subterrânea. Revista Brasileira de Milho e Sorgo, v.5, n.3, p.382-394, 2006. <http://rbms.cnpms.embrapa.br/index. php/ojs/article/view/200/200>. 20 Nov. 2012.

Weber, M. A.; Mielniczuk, J. Estoque e disponibilidade de nitrogênio no solo em experimento de longa duração. Revista Brasileira de Ciência do Solo, v.33, n.2, p.429-437, 2009. $<$ http://dx.doi.org/10.1590/S0100-06832009000200020>. 